\title{
Carrying on or giving in: The role of automatic processes in ego-depletion
}

Citation for published version (APA):

Alberts, H. J. E. M., Martijn, C., Greb, J., Merckelbach, H., \& de Vries, N. K. (2007). Carrying on or giving in: The role of automatic processes in ego-depletion. British Journal of Social Psychology, 46(Pt 2), 383399. https://doi.org/10.1348/014466606X130111

Document status and date:

Published: 01/01/2007

DOI:

10.1348/014466606X130111

Document Version:

Publisher's PDF, also known as Version of record

Document license:

Taverne

Please check the document version of this publication:

- A submitted manuscript is the version of the article upon submission and before peer-review. There can be important differences between the submitted version and the official published version of record.

People interested in the research are advised to contact the author for the final version of the publication, or visit the DOI to the publisher's website.

- The final author version and the galley proof are versions of the publication after peer review.

- The final published version features the final layout of the paper including the volume, issue and page numbers.

Link to publication

\footnotetext{
General rights rights.

- You may freely distribute the URL identifying the publication in the public portal. please follow below link for the End User Agreement:

www.umlib.nl/taverne-license

Take down policy

If you believe that this document breaches copyright please contact us at:

repository@maastrichtuniversity.nl

providing details and we will investigate your claim.
}

Copyright and moral rights for the publications made accessible in the public portal are retained by the authors and/or other copyright owners and it is a condition of accessing publications that users recognise and abide by the legal requirements associated with these

- Users may download and print one copy of any publication from the public portal for the purpose of private study or research.

- You may not further distribute the material or use it for any profit-making activity or commercial gain

If the publication is distributed under the terms of Article $25 \mathrm{fa}$ of the Dutch Copyright Act, indicated by the "Taverne" license above, 


\title{
Copyright (C) The British Psychological Society
}

Reproduction in any form (including the internet) is prohibited without prior permission from the Society

\begin{tabular}{|c|c|c|}
\hline $\begin{array}{r}\text { British Journal of Social Psychology (2007), 46, 383-399 } \\
\text { (c) } 2007 \text { The British Psychological Society }\end{array}$ & 站 & $\begin{array}{l}\text { The } \\
\text { British } \\
\text { Psychological } \\
\text { Society }\end{array}$ \\
\hline & www.bpsjo & nals.co.uk \\
\hline
\end{tabular}

\section{Carrying on or giving in: The role of automatic processes in overcoming ego depletion}

\author{
Hugo J. E. M. Alberts*, Carolien Martijn, Judith Greb, \\ Harald Merckelbach and Nanne K. de Vries \\ Universiteit Maastricht, The Netherlands
}

\begin{abstract}
Research has shown that repeated exercise of self-control leads to impaired performance on subsequent self-control tasks, a phenomenon labelled ego depletion. The current research investigates the influence of automatic processes on self-control performance. Study I shows that activation of persistence leads to stable self-control performance and may help to overcome effects of ego depletion. Initially depleted participants kept their physical self-control performances constant when primed with persistence. If such a prime was absent, self-control performance of depleted participants decreased indicating ego depletion. Using a different manipulation, these findings were replicated in Study 2.
\end{abstract}

Self-control entails the override or inhibition of urges, behaviours or desires (Barkley, 1997; Baumeister, Heatherton, \& Tice, 1994; Shallice \& Burgess, 1993) and can be regarded as an essential ingredient for many successes and achievements in life. Recent developments in the field of self-control suggest that self-control is costly (Baumeister, Bratslavsky, Muraven, \& Tice, 1998). According to Muraven and colleagues, the capacity to control ourselves is defined by our own restrictions (Muraven \& Baumeister, 2000; Muraven, Tice, \& Baumeister, 1998). These restrictions are a direct consequence of selfcontrol drawing on a fixed and limited resource, akin to strength or energy. After an act of self-control, the resource becomes temporarily depleted, leaving the individual in a state of ego depletion. Therefore, performance on a subsequent self-control act will be impaired because of lack of resources. In the current paper, we focus on ways to overcome the effects of ego depletion and to improve self-control performance.

The literature on ego depletion ascribes a number of features to the concept of energy resource. First, the resource is non-specific and used for a broad variety of selfcontrol operations, such as overriding or inhibiting impulses, regulating emotions, making choices and so on. Second, the resource is limited, that is, the energy required to inhibit the desire to eat a fattening snack is no longer available to suppress a negative emotion. Third, the resource is similar to a muscle in the way that self-control becomes

*Correspondence should be addressed to Hugo Alberts, Universiteit Maastricht, Faculty of Psychology, Experimental Psychology, PO Box 616, 6200 MD Maastricht, The Netherlands (e-mail: h.alberts@psychology.unimaas.nl). 


\section{Copyright (C) The British Psychological Society \\ Reproduction in any form (including the internet) is prohibited without prior permission from the Society}

Hugo J. E. M. Alberts et al.

tired after use and needs rest to recover. Today, a wide range of studies have, indeed, shown that when people exert self-control, performance on a subsequent act of selfcontrol is likely to decrease (cf. Baumeister et al., 1998; Ciarocco, Sommer, \& Baumeister, 2001; Muraven et al., 1998). Together, the results of these studies illustrate that, after repeated self-control, ego depletion seems to emerge automatically, causing almost inevitable failure of future self-control attempts.

Given the advantages of successful self-control, an important question is whether the negative effects of ego depletion can be prevented. To date, most studies on self-control and ego depletion focused on the conditions under which ego depletion occurs and only a few studies investigated if and how ego depletion may be prevented or counteracted. A first study by Muraven et al. (1998) showed that self-control may be strengthened by a regime of training. Students were instructed to engage in self-control trainings (such as keeping food diaries or improving posture) for a 2 -week period. After that period, students showed improved performance on a physical self-control measurement when compared with a control group. Martijn, Tenbült, De Vries, Dreezens, and Merckelbach (2002) demonstrated another way to overcome the negative effects of ego depletion, namely by changing people's expectancies. In this study, participants watched a highly disgusting video fragment and were asked to suppress their emotions. A control group watched the same video, but received no suppression instructions. Immediately after, half of the participants who suppressed their emotions were informed that 'often people think they have to rest after an effortful task. However, scientific investigations prove that this is not the case after emotional effort' (Martijn et al., p. 446, Expt 1). On a subsequent self-control demanding task, participants who received this information outperformed control participants and participants who received no such information. Ego depletion may also be compensated by increasing people's motivation to perform well on a subsequent self-control task. A recent series of experiments by Muraven and Slessarava (2003) demonstrated that depleted individuals persevered longer at a subsequent self-control task if they were led to believe that their persistence would be beneficial to others or to themselves. Depleted participants, who were not motivated, lowered their persistence and thus showed ego depletion.

To sum up, recent studies on overcoming ego depletion showed that self-control can be improved by various means, such as training or explicitly increasing the benefits of enacting self-control. Although the above-described studies use different manipulations to improve self-control, they share the way these manipulations are presented; all studies use explicit manipulations, requiring a certain amount of conscious attention and processing. An important question in the light of these findings is whether ego depletion can only be diminished or even eliminated by ways that depend on conscious attention or conscious processing. In other words, is it possible to circumvent the necessity of conscious self-control?

In the present series of experiments, we try to extend the current findings on selfcontrol and ego depletion by investigating whether the emergence of ego depletion can be reduced or even eliminated by means of manipulations that are known to operate at an automatic level and do not require conscious awareness to be effective. More precisely, we will investigate whether activation of the concept of persistence can help to prevent loss of self-control. As described by Baumeister, Muraven, and Tice (2000; see also Schmeichel, Vohs, \& Baumeister, 2003, p. 87), ego depletion is not a sign of complete exhaustion, but a tendency to conserve a remaining amount of energy. However, Baumeister and colleagues do not mention whether strength conservation involves a conscious and deliberate decision or a more or less automatic process that does not 


\section{Copyright (C) The British Psychological Society \\ Reproduction in any form (including the internet) is prohibited without prior permission from the Society}

necessarily require conscious awareness. In our opinion, the latter view is most likely to be true. In this view, the tendency to conserve resources can best be interpreted as a standard or default reaction after enactment of self-control. After an act of self-control, people may automatically switch to a standby or 'energy conservation' mode that enables them to them to deal in the most careful way with the remaining amount of energy. If the reaction of depleted individuals to future self-control attempts is guided by this standby modus, then it seems worthwhile to know whether and how it is possible to switch to the 'full operation' mode again. Previous research of Webb and Sheeran (2003) provided preliminary evidence suggesting that automatic processes can help to overcome the effects of ego depletion. The influence of automaticity was demonstrated by using implementation intentions (Gollwitzer, 1999). These are action plans and refer to specific goal behaviour as well as to the situational context in which the planned behaviour will be enacted (e.g. 'when I encounter situation $\mathbf{x}$, I will initiate goal-directed behaviour $\mathbf{y}$ '). Since behavioural control is overtaken by anticipated environmental cues, the process of control becomes automated. In two experiments, it was consistently found that participants who formed implementation intentions that specified when and how to act during a depletion task performed significantly better on a subsequent self-control task than depleted participants who did not form these implementation intentions. In other words, implementation intentions conserved self-regulatory resources.

In the present study, we examined whether activation of concepts related to the maintenance of control behaviour, such as persistence, is also capable of offsetting the effects of ego depletion. Whereas previously discussed studies on self-regulation and automatic goal pursuit mainly addressed activation of self-regulatory goals (e.g. Bargh, Gollwitzer, Lee-Chai, Barndollar, \& Troetschel, 2001; Shah \& Kruglanski, 2002), the present study focuses on activation of self-regulatory behaviour. Instead of applying directly to one specific (self-regulatory) goal, persistence is clearly a behavioural construct that is (a specifically) related to the maintenance of control behaviour in general. Activation of persistence may produce automatic control behaviour and, hence, circumvents the need for active and conscious self-regulation. Because of the absence of such need, this may be particularly useful for individuals who already suffer from resource depletion. In order to activate persistence, we used different priming procedures. In a series of experiments by Bargh, Chen, and Burrows (1996), it was already shown that, when a trait construct or stereotype is activated by means of a priming procedure, behaviour changes accordingly, even in an unrelated context. That is, the thought of a specific behaviour was sufficient to increase the tendency to behave in that way. Likewise, in the present series of studies, we expect self-control related behaviour to be affected by activation of persistence. We expect that low depleted participants outperform high depleted participants. We also hypothesize that, under the condition of ego depletion, activation of persistence leads to relatively better self-control performance than no activation of persistence. In Study 1, low and high depleted participants were primed with persistence related concepts such as 'perseverance' and 'holding on' by means of a scrambled sentences procedure. Study 2 aimed to replicate these findings and activated persistence by means of a visual priming procedure.

\section{STUDY I}

The aim of the first study was to investigate whether activation of 'persistence' improves people's self-control performance. The first part of the study consisted of the manipulation of initial self-control induced by presenting participants either with 


\section{Copyright (C) The British Psychological Society \\ Reproduction in any form (including the internet) is prohibited without prior permission from the Society}

Hugo J. E. M. Alberts et al.

eight solvable, but extremely difficult labyrinths (high self-control) or 39 relatively easy labyrinths (low self-control). The labyrinths were selected on the basis of a pilot study. That study showed that difficult labyrinths were judged as significantly more difficult and almost impossible to solve as compared with easy labyrinths. Moreover, pilot participants expressed that they wished to quit solving difficult labyrinths after a few minutes and judged the task as exacting. ${ }^{1}$ Although in a different form, a conceptually similar manipulation to induce ego depletion was used in a study by Baumeister $\mathrm{et}$ al. (1998), who exposed food-deprived participants to desirable but forbidden food for a fixed period of 5 minutes. Persisting with unattractive actions, such as solving difficult labyrinths or refraining from tempting food, while one experiences the urge to quit can be regarded as a task that requires self-control.

The second part of the study intended to increase the salience of self-control enhancing behaviour by means of priming. Half the participants were presented with a scrambled sentence task (SST; Srull \& Wyer, 1979), including sentences related to persistence and perseverance, holding on and so on, whereas the other half received a SST with neutral sentences (see also Araya, Akrami, Ekehammer, \& Hedlund, 2002). We chose a SST because it is an implicit priming technique that reduces demand characteristics or other self-presentational concerns (Bargh \& Chartrand, 2000).

The third task of the study was a physical stamina task adapted from Muraven et al. (1998) and consisted of squeezing a handgrip. Although squeezing a handgrip seems primarily a matter of muscular strength, it has proved to be a successful measure of selfcontrol in prior research (see e.g. Ciarocco et al., 2001, Study 2; Muraven et al., 1998, Study 1). Because squeezing a handgrip becomes tiring after a short period of time, the person feels the urge to stop squeezing. Overcoming this fatigue and overriding the urge to quit requires self-control. We adopted the physical stamina measure as the main dependent variable for two reasons. First, because most people think that a handgrip primarily depends on muscular strength, it is a relatively unobtrusive measure of self-control. Second, because squeezing a handgrip is quite distinct from the tasks we used in this experiment to induce depletion and to prime persistence, participants were less likely to suspect any connection between the tasks. In order to be able to control for individual differences in hand strength, handgrip performance was measured twice, before the labyrinths task and after the SST. Because of this baseline measurement, all participants started with a selfcontrol task and thus exercised some self-control before starting with the actual self-control manipulation (easy vs. difficult labyrinths). Thus, strictly speaking the comparison was between groups of participants that differed in their level of depletion.

Our hypothesis was that participants who exercised initial self-control would perform better on a subsequent self-control task under conditions of high accessibility of persistence than under conditions of low accessibility of persistence.

\footnotetext{
' Labyrinths were pre-tested in an unrelated sample of 16 participants. Each participant received a 15-page booklet with a different labyrinth printed on each page: half of the booklets consisted of I5 extremely difficult labyrinths, the other half of I5 relatively easy labyrinths. Each participant was allowed to work for exactly 10 minutes on the labyrinths and was then asked to evaluate the extent to which they judged the labyrinths as difficult and frustrating, and whether they had wanted to quit the task before the 10 minutes were over. Judgments were gathered on three 5-point scales varying from I = not at all, $5=$ very much. In the difficult labyrinth condition, only one participant completed the first labyrinth; the other seven did not manage to solve one labyrinth within 10 minutes. In the easy labyrinth condition, participants solved I3.2 (SD = I.4) on average. This was reflected in the judgments of the difficulty level of the labyrinths ( $M$ difficult $=4.3, M$ easy $=1.5$, $t(I 4)=8,78, p<.0 I$ ) and frustration (M difficult $=3 . I$, M easy $=1.6, t(I 4)=3.14, p<.0 I)$. Moreover, participants who tried to solve difficult labyrinths indicated a stronger desire to quit the task earlier than allowed ( $M$ difficult $=3.3, M$ easy $=1.9, t(14)=2.28, p<.05)$.
} 


\section{Copyright (C) The British Psychological Society \\ Reproduction in any form (including the internet) is prohibited without prior permission from the Society}

Overcoming ego-depletion and self-control

\section{Method \\ Participants and procedure}

Eighty (72 women and 8 men) undergraduates of the University of Maastricht were randomly assigned to a 2 (self-control: easy vs. difficult labyrinths) $\times 2$ (priming: neutral SST vs. persistence related SST) between-subjects design. Participants were individually tested in 30-minute sessions and received a monetary reward for their participation. In order to minimize experimenter effects, the experimenter used a written protocol throughout the whole experimental procedure (all instructions to participants were equal). The experiment was approved by the standing ethical committee of our faculty.

After a short and neutral briefing on the study ('This study consists of a series of unrelated cognitive and physical tasks'), participants performed the first physical selfcontrol measurement that functioned as an individual baseline against which to compare the second physical self-control measure. The experimenter asked participants to place a handgrip in their dominant hand and inserted a coin between the two handles as the participant squeezed them together. Participants were instructed to squeeze the handgrip for as long as possible. The moment a participant relaxed his or her grip, the coin fell out. The experimenter started a stopwatch at the moment he placed the coin between the handles and stopped timing when the coin fell out.

Following the first handgrip task, participants received a booklet with relatively easy labyrinths (low self-control) or extremely difficult labyrinths (high self-control). They were instructed to solve as many labyrinths as possible within 10 minutes. After finishing the labyrinths, participants filled out the Brief Mood Inspection Scale (BMIS; Mayer \& Gaschke, 1988) containing 16 items and 6 items that were added to obtain additional data about the energy and tiredness component of participants' mood. In total, there were eight (two original BMIS and six extra) items pertaining to tiredness. Subsequently, we induced high accessibility of persistence by presenting a 'verbal ability task'. In fact, this was a SST intended to prime participants with the concept of persistence. Participants unscrambled 25 scrambled sentences of which 15 were related to persistence (e.g. 'Peter keeps going'); the other 10 were neutral and were not related to persistence or self-control (e.g. 'Sam buys bread'). Persistence related and neutral sentences were presented in a random order that was the same for all participants in the persistence prime condition. Participants in the neutral priming condition received 25 neutral scrambled sentences. A pilot study revealed that the writing activity during the scrambled sentence task interfered with performance on the subsequent handgrip task. A majority of pilot participants indicated that their poor performance on the second handgrip task was due to their fast speed of writing during the SST. Therefore, we adapted the procedure and asked participants just to read the correct sentences aloud. After completing the SST, participants squeezed the handgrip for the second time, following the same procedure as for the first handgrip measurement. Next, participants once more completed the eight-item 'energy and tiredness' mood scale. This scale consisted of two original BMIS adjectives related to energy and tiredness and the six additional items. Participants were finally asked to write down what they thought the experiment was about. The latter served to determine whether participants were aware of a possible influence of the SST. Participants were debriefed and thanked.

\section{Dependent measures}

The Dutch translation of the BMIS (Mayer \& Gaschke, 1988) was used to check for a possible difference in mood between participants in the easy and difficult labyrinth 


\section{Copyright (C) The British Psychological Society \\ Reproduction in any form (including the internet) is prohibited without prior permission from the Society}

conditions (Cronbach's $\alpha=.85$ ). The BMIS is a selection of 16 adjectives tapping eight mood states: (a) happy (bappy, lively), (b) loving (loving, caring), (c) calm (calm, content), (d) energetic (active, peppy), (e) fearful/anxious (jittery, nervous), (f) angry (grouchy, fed up), (g) tired (tired, drowsy) and (h) sad (gloomy, sad). The Dutch translation of the BMIS was scored on 16 five-point scales ranging from (1) definitely not feel to (5) definitely feel. Six additional items were scored on the same five-point scales in order to obtain additional information about the energy and tiredness component of participants' mood (Cronbach's $\alpha=.88$ ). These items were I feel fit/I feel that I can bandle the world/I feel lethargic/I feel exhausted/I feel not like doing anything/I feel dull. The total mood scale was completed directly after the first physical self-control measure. After the second physical self-control measure, a selection consisting of two original BMIS adjectives and the six additional items was administered, all pertaining to energy and tiredness (Cronbach's $\alpha=.90$ ).

In order to control for individual differences, physical performance was measured twice, at the beginning of the experiment and directly after the labyrinth task. Using a stopwatch, the time (in milliseconds) was measured that a participant squeezed the handles of the handgrip together.

\section{Results}

First, we checked whether any of the participants in the experimental SST condition were aware of the fact that the majority of these sentences were related to persistence. Not a single participant recognized the specific content of the sentences. Hence, none of our participants was aware of the main hypothesis of the experiment about the relation between activating persistence and reducing ego depletion.

Four participants had deviant scores on the first handgrip time $(z>3)$ and were recognized as outliers (outlier procedure; cf. Ciarocco et al., 2001). Therefore, further analyses described below included the data of the remaining 76 participants (easy labyrinths + neutral prime $N=19$, easy labyrinths + persistence prime $N=18$, difficult labyrinths + neutral prime $N=19$ and difficult labyrinths + persistence prime $N=20$ ).

In order to check the effectiveness of our self-control manipulation, we tested whether solving difficult labyrinths consumed more self-control than easy labyrinths. To test this, we compared within the neutral priming conditions the handgrip performance of participants who solved difficult labyrinths (high self-control) with the performance of participants who solved easy labyrinths (low self-control). As expected, an ANOVA with the mean scores of the two handgrip times as a repeated measurement factor and initial self-control as the between-subject factor revealed a significant interaction effect of the two factors, $F(1,36)=7.37, p=.01, \eta^{2}=.17$. Under neutral priming conditions, participants who were exposed to the difficult labyrinths performed significantly worse than those who solved the relatively easy labyrinths (Ms handgrip $2-$ handgrip $1=-13.54$ vs. 0.17 , and $S D s=15.64$ vs. 15.51 , respectively). Moreover, in order to investigate the alternative explanation that the above-described differences in performance can be explained in terms of excessive performance on the first measurement or second measurement, we calculated correlations between the first and second measurement within the neutral priming condition for high and low initial self-control participants separately. Analysis ruled out this alternative explanation by revealing a comparable and significant positive correlation between the two measures in the high self-control condition as well as in the low self-control condition $(r=.72$, $p<.01$ vs. $r=.71, p<.01$, respectively). 


\section{Copyright (C) The British Psychological Society \\ Reproduction in any form (including the internet) is prohibited without prior permission from the Society}

One-way ANOVA with condition as the independent variable and time on handgrip 1 as the dependent variable checked for initial differences in handgrip strength and yielded a marginally significant effect, $F(3,75)=2.54, p=.06, \eta^{2}=.10$. Although only marginally significant, this effect might imply that differences in self-control performance at Time 2 were the result of intergroup differences in the initial time measurement instead of changes across groups. For this reason, in all further analyses of self-control performance, handgrip 1 was included as a covariate in order to control for pre-existing personal differences in handgrip strength.

Multiple regression analyses were used to test the main hypothesis that, under the condition of ego depletion, activation of persistence leads to relatively better selfcontrol performance than no activation of persistence. Multiple linear regression was utilized since it permits the specification of which comparisons are made without any loss or reduction of statistical power. In line with the two-way design of the study, both the factors initial self-control and priming were dummy coded, comparing main effects of initial self-control and priming, plus their interaction.

Regression analyses revealed a main effect of initial self-control, $\beta=0.20$, $t(75)=2.36, p=.02$, indicating the standard ego depletion effect. That is, participants who solved difficult labyrinths (high initial self-control) performed worse at the second handgrip measurement than participants who received easy labyrinths. A second main effect found was type of priming, $\beta=-0.23, t(75)=2.86, p<.01$. Participants who received a persistence prime performed relatively better at the second handgrip measurement than participants who received a neutral prime. The two-way interaction failed to reach significance, $\beta=-0.05, t(75)=0.60$. As can be seen from Table 1 , in which the handgrip performances per condition are summarized, the absence of the interaction is caused by the fact that both the difficult and easy labyrinth conditions profited from the persistence prime.

Table I. Self-control performance in Study I

\begin{tabular}{llcr}
\hline Condition & Time I & Time 2 & Change \\
\hline Difficult labyrinths + neutral prime & $53.13(21.30)$ & $39.59(20.37)$ & - I3.54 (I5.64) \\
Difficult labyrinths + persistence prime & $40.24(28.44)$ & $39.46(27.76)$ & $-0.78(19.17)$ \\
Easy labyrinths + neutral prime & $31.28(21.69)$ & $31.46(18.40)$ & $0.17(15.5 I)$ \\
Easy labyrinths + persistence prime & $38.60(27.0)$ & $50.32(29.33)$ & II.72 (23.33) \\
\hline
\end{tabular}

Note. Numbers under Time I and Time 2 represent mean times that participants squeezed the handgrip, in seconds. Standard deviations are given in parentheses. Numbers under Change represent change in performance, in seconds, from Time I to Time 2.

One-way ANOVA revealed that solving easy versus difficult labyrinths resulted in mood differences, $F(1,75)=9.45, p<.01, \eta^{2}=.11$. Participants who solved easy labyrinths reported a somewhat better mood than those who solved difficult labyrinths ( $M$ s $=3.68$ vs. 3.46 and $S D s=0.30$ and 0.34 , respectively). To investigate the possible influence of this mood effect on self-control performance, we included mood as a covariate in the previously described regression model.

Most important, the covariate mood was found non-significant, $\beta=-0.12$, $t(75)=1.25, p=.22$. The remaining effects replicated our previous pattern; although the effect of initial self-control was non-significant, it directionally supported our previous pattern of results, $\beta=0.12, t(75)=1.65, p=.11$. In addition, a main effect 


\section{Copyright (C) The British Psychological Society \\ Reproduction in any form (including the internet) is prohibited without prior permission from the Society}

Hugo J. E. M. Alberts et al.

for type of priming was found significant again, $\beta=-.25, t(75)=3.10, p<.01$. No interaction effect was found, $\beta=-.029, t(75)=.35, p=.73$. These results suggest that differences in mood cannot fully account for the significant differences in selfcontrol performance between conditions.

To investigate the possible influence of the priming procedure on participants' mood, we analysed the eight-item 'energy and tiredness' mood scale obtained directly after the second handgrip. This revealed that exposure to neutral or persistence primes did not lead to a significant difference in reported mood, $F(1,75)<1.0, \eta^{2}=.011$ $(M \mathrm{~s}=3.58$ vs. 3.49 , and $S D s=0.42$ vs. 0.45 , respectively).

Furthermore, changes in mood were analysed by evaluating the difference between the second 'energy and tiredness' mood scale and the same eight items of the first mood questionnaire. ANOVA did not result in any significant main or interaction effects (all $p s>.05)$. The absence of changes in mood indicated that participants did not experience a change in mood during the course of the experiment.

In order to test the possible influence of mood changes on the performance on the physical self-control task, we included the difference between the second 'energy and tiredness' mood scale and the same eight items of the first mood questionnaire as a covariate in the regression analysis. Again, a significant main effect of initial selfcontrol, $\beta=0.19, t(75)=2.29, p=.025$, as well as type of priming was found, $\beta=-0.23, t(75)=2.85, p<.01$. In addition, no significant interaction effect was found, $\beta=0.05, t(75)=.60, p=.56$, whereas the covariate failed to reach significance, $\beta=0.01, t(75)=.09, p=.93$. These results indicate that the differences in physical self-control performance cannot be attributed to changes in mood.

\section{Discussion}

The data of Study 1 provided support for the hypothesis that increasing the accessibility of persistence may help to overcome effects of ego depletion.

Participants in both the high and low self-control condition kept their performance relatively stable as a result of priming. The findings indicate that initially depleted participants kept their physical self-control performances constant when primed with persistence. In the absence of such a prime, physical self-control performance of depleted participants went down, indicating the standard effect of ego depletion. Thus, although the interaction between $\mathrm{x}$ and $\mathrm{y}$ was non-significant, the pattern of means was in the predicted direction. In addition, the pattern of results of Study 1 suggests that the effect of ego depletion is not fixed or absolute, but nevertheless persistent. Low depleted participants who were exposed to a persistence prime outperformed high depleted participants who were exposed to the same priming manipulation. The finding that these groups differ can be held as an indication of fatigue or depletion. However, this effect of fatigue is not absolute. After all, high depleted participants who were primed with persistence performed better than high depleted participants who received a neutral prime.

Another important aspect with regard to the findings of Study 1 concerns the effect of priming of persistence on future self-control demands. Does the finding that no signs of ego depletion are present when people are depleted and exposed to the persistence prime indicate that ego depletion has been reduced or even eliminated, or does this finding implicate that a delay of ego depletion has occurred? According to the theoretical assumptions of the limited strength model, one may assume that depleted participants who were primed with persistence should have used more of their (last) 


\section{Copyright (C) The British Psychological Society \\ Reproduction in any form (including the internet) is prohibited without prior permission from the Society}

Overcoming ego-depletion and self-control

energy resources in order to be able to keep their self-control performance stable (cf. Muraven \& Slessarava, 2003). This explanation was exploratorily examined in Study 2.

\section{STUDY 2}

In order to test the assumption that depleted participants who are primed with persistence use more of their (last) energy resources, the experimental procedure of Study 2 was extended with an additional task. When depleted, people display a shift towards preferring activities that require less effort (Holding, 1983). Moreover, as suggested by Muraven and Slessarava (2003), the decision to invest effort in a task strongly depends on a person's motivation for that task and his or her perception of the amount of energy left. Therefore, a task was selected that would be sensitive to such appraisals, and participants were asked to indicate the preferred difficulty level for the last task. We reasoned that if priming of persistence causes people to invest more energy, this extra investment of energy should be reflected in a decreased willingness to invest in a third self-control task. As a consequence, people who were primed with persistence were expected to prefer a relatively lower difficulty of an additional task.

In summary, Study 2 was designed to provide converging evidence with the results of Study 1 and to investigate the effect of priming on future self-control demands. Although we relied on the same experimental procedure as in Study 1, some changes were made. Besides the addition of an extra task, we also used an alternative ego depletion manipulation and an alternative way to increase the accessibility of 'persistence'. In Study 2 , ego depletion was induced by means of an attention control task and, instead of a verbal priming procedure, we used a visual priming procedure. In other respects, the study's experimental procedure was similar to that in Study 1. As in Study 1, a depleting task was followed by a muscular endurance test. Performance on this physical self-control task represented the main dependent variable. We anticipated that depleted participants who were primed with 'persistence' would perform relatively better on the second muscular endurance task than depleted participants who received no such prime.

\section{Method \\ Participants and procedure}

Eighty undergraduates of the University of Maastricht (60 women and 20 men) were randomly assigned to one of four conditions that consisted of a 2 (self-control: low vs. high) $\times 2$ (type of prime: neutral prime vs. persistence prime) between-subjects design. All participants were individually tested in 40-minute sessions. During the whole experimental procedure, the experimenter used a written protocol in order to minimize experimenter effects. The experiment was approved by the standing ethical committee of our faculty.

The experiment was presented as a series of unrelated tasks that tested participants' cognitive and physical abilities. After signing a consent form, all participants took part in the muscular endurance test to furnish a baseline against which to compare the second endurance task. Participants were instructed to hold a 1.5-kilogram weight for as long as possible with their arm stretched at a $90^{\circ}$ angle with their torso while sitting on a chair in front of a computer screen. They were situated in such a way that the hand holding the weight was exactly 5 centimetres above a bell. When participants were not able to hold the weight in the described position any longer, their arm dropped and consequently the weight hit the bell. The experimenter stopped timing when the bell rang. 


\section{Copyright (C) The British Psychological Society \\ Reproduction in any form (including the internet) is prohibited without prior permission from the Society}

Next, high self-control was induced through an attention control task. This 8-minute task required participants to calculate and name the sum of digits presented on a computer screen. The difficulty of the calculations increased throughout the task. In the high attention-control conditions, these calculations involved various two-digit numbers. Additionally, subjects were auditively distracted while performing the task: by means of headphones, participants were exposed to a voice randomly naming one and two number digits and thereby interfering with their calculations. Thus, participants in the attentioncontrol conditions had to focus their attention on the calculations on the screen and try to override their impulse to listen to the interfering noise. In the no attention-control condition, participants summed combinations of two one- or two-digit numbers without being exposed to auditory interference. Hence, participants could successfully perform the (relative easy) calculations without having to ignore the interfering stimuli. Similar manipulations of attention control have been successfully used to elicit depletion in previous studies of self-regulatory resources (Faber \& Vohs, 2004; Schmeichel et al., 2003). After finishing the calculations, participants filled out the first mood scale which included 16 items of the Brief Mood Inspection scale (Mayer \& Gaschke, 1988; Cronbach's $\alpha=.86$ ) and six additional items concerning the energy and tiredness component of participants' mood (Cronbach's $\alpha=.87$ ).

Subsequently, regulatory performance was measured again. Participants were seated in front of the computer screen and held the 1.5-kilogram weight with an outstretched arm. At this point, the visual priming manipulation took place. Suddenly, while participants were holding the weight, the experimenter activated (by inconspicuously pressing a button) a screensaver which appeared on the computer screen. Participants were led to believe that this screensaver appeared by accident. In the persistence prime condition, the screensaver depicted a winning young man in a business suit and a logo saying: 'www.you-can-do-it.com, wallpapers and screensavers'. In the neutral prime condition, the screensaver showed a picture of a vase and a similar logo saying: 'www.myscreensaver.com, wallpapers and screensavers'. Next, participants completed an eight-item 'energy and tiredness' mood scale (see Study 1; Cronbach's $\alpha=.84$ ).

Thereafter, participants were asked to perform the final task. The experimenter explained that the next task varied in level of difficulty and asked participants to choose a difficulty level ranging from very easy (1) to very hard (5). They were led to believe that the level they selected represented a corresponding task difficulty. In fact, all participants received the same task, irrespective of their choice of a particular difficulty level. This final task was presented in a booklet and consisted of two pairs of drawings that were almost the same, but with a certain number of differences. The participants' goal was to detect and report these differences.

Finally, a short questionnaire was used to determine whether participants recognized the true nature of the study. To assess the effectiveness of our depletion manipulation, participants were also asked to what extent they thought the calculation task was dull, easy and required mental effort. After completing these final questionnaires, participants received a careful debriefing and were probed for any questions or concerns.

\section{Dependent measures}

Most of the dependent measures were identical to Study 1. As in Study 1, performance on a physical task served as the main dependent variable. Besides the questionnaires concerning mood, we also included a manipulation check in the form of a short questionnaire about the depletion task. 


\section{Copyright (C) The British Psychological Society \\ Reproduction in any form (including the internet) is prohibited without prior permission from the Society}

To investigate whether prior exercise of self-control might cause people to prefer a task with lower difficulty, we registered the difficulty level participants chose. The selected level (1-5) on the last task represented the dependent measures on this task.

\section{Results}

No participants showed deviant scores on the first physical measurement $(z>3)$. Therefore, all 80 participants were included in the analyses.

\section{Manipulation checks}

As far as can be inferred from the description of the study given in their own words in the final questionnaire, none of the participants realized the true purpose of the experiment. In general, participants regarded the link between difficult tasks and physical power' as the main purpose of the current experiment. On a five-point scale, participants rated the distraction calculation task as relatively more exhausting than the no distraction calculation task $(M=2.9, S D=0.70$ vs. $M=2.3, S D=0.84$, respectively), $F(1,79)=13.12, p<.01, \eta^{2}=.14$. Meanwhile, participants liked the distraction $(M=3.3, S D=0.98)$ and the no distraction calculation task $(M=3.6$, $S D=0.63)$ equally well, $F(1,79)=2.5, p=.12, \eta^{2}=.03$. Likewise, the distraction calculation task was rated equally interesting $(M=3.3, S D=0.84)$ as the no distraction calculation task $(M=3.4, S D=0.86), F(1,79)<1.0, \eta^{2}=.004$.

In order to investigate whether the attention control task successfully induced ego depletion, we compared the physical performance of participants who solved difficult calculations with the performance of participants who solved easy calculations under neutral priming conditions. An ANOVA with the mean scores of the first and second physical measurement as a repeated measurement factor and initial self-control as a between-subject factor revealed a significant interaction effect of these two factors, $F(1,38)=26.15, p<.01 \eta^{2}=.41$. This suggests that the attention control task successfully induced ego depletion (Ms physical measurement 2 - physical measurement $1=-5.07$ vs. -17.68 , and $S D$ s $=6.11$ vs. 9.17 , respectively). Additional analyses revealed a significant correlation between the two physical measures in the depletion condition, as well as in the no depletion condition $(r=.97, p<.01$ vs. $r=.98, p<.01$, respectively). This rules out the possibility that lowered performance on the second handgrip measurement should be attributed to relative extreme effort on the first measurement or vice versa. One-way ANOVA showed that the scores on the first physical task did not differ by condition, $F(1,79)<1.0, \eta^{2}=.002$.

Regression analyses were conducted in order to analyse the effects of initial selfcontrol (easy vs. difficult calculations) and priming (persistence prime vs. neutral prime) on self-control performance. As in Study 1, the main dependent variable, self-control performance, was measured by entering the second physical measurement as the dependent variable whereas the first measurement was included as the covariate in the regression analyses. In order to compare main effects of initial self-control and priming and to analyse their interaction, initial self-control and priming were dummy coded.

Regression analyses revealed a main effect for initial self-control, $\beta=0.11$, $t(79)=3.67, p<.01$, and a main effect for priming, $\beta=-0.20, t(79)=6.66, p<.01$. More important, an interaction effect of physical self-control (holding the weight), initial self-control and priming was found, $\beta=0.081, t(79)=2.70, p<.01$. Mean times on both physical self-control performances and their difference per condition are summarized in Table 2. 


\section{Copyright (C) The British Psychological Society}

Reproduction in any form (including the internet) is prohibited without prior permission from the Society

Table 2. Self-control performance in Study 2

\begin{tabular}{lccc}
\hline Condition & Time I & Time 2 & Change \\
\hline Difficult calculations + neutral prime & $72.12(43.42)$ & $57.44(42.50)$ & - I7.68 (9.17) \\
Difficult calculations + persistence prime & $77.04(37.42)$ & $77.35(28.4 I)$ & $0.31(11.42)$ \\
Easy calculations + neutral prime & $74.90(31.54)$ & $69.83(28.6 I)$ & $-5.08(6.11)$ \\
Easy calculations + persistence prime & $72.66(34.53)$ & $75.51(29.92)$ & $2.85(12.94)$ \\
\hline
\end{tabular}

Note. Numbers under Time I and Time 2 represent mean times that participants squeezed the handgrip, in seconds. Standard deviations are given in parentheses. Numbers under Change represent change in performance, in seconds, from Time I to Time 2.

In order to explore this interaction effect further, dummy coding was used to compare self-control performance among the four groups. First, we compared the effect of priming within the two high initial self-control conditions, which were dummy coded as -1 and 1 , whereas the two low initial self-control conditions were both coded as 0 . Regression analysis revealed a significant effect, $\beta=-0.20, t(79)=5.87, p<.01$. Depleted participants who were exposed to the persistence prime outperformed depleted participants who received a neutral prime. Next, the effect of priming for individuals who exerted low initial self-control was investigated by dummy coding the two low initial self-control conditions as -1 and 1 and the two low initial self-control conditions as 0 . Again, a significant effect was found, $\beta=-0.12, t(79)=3.18, p<.01$, indicating that within the low initial self-control conditions, participants who were exposed to the persistence prime performed significantly better than those who received the neutral prime. Moreover, our main prediction was that under conditions of high self-control, handgrip performances will not suffer from ego depletion when offered a persistence-related prime. Also, under conditions of low self-control, handgrip performances were also expected to remain stable. Thus, a decrease in handgrip times was only predicted for participants who exercised high initial self-control and who received a neutral prime. Therefore, regression analysis was performed in which the difference between the two handgrip performances of the high self-control, neutral prime participants (dummy coded as 3) was tested against the other three conditions (each condition dummy coded as -1 ). Results showed that decline in self-control performance of high self-control participants who were exposed to the neutral prime was significantly greater than the decline in performance of the other three conditions, $\beta=-0.22, t(79)=7.19, p<.01$.

In contrast to Study 1, we found that solving easy or difficult calculations did not result in a mood difference, $F(1,79)<1.0, \eta^{2}=.03$. This makes it unlikely that differences in physical self-control measurements between the four conditions can be attributed to a mood effect.

A one-way ANOVA on the eight-item 'energy and tiredness' mood scale questionnaire, taken directly after the second physical task, revealed that exposure to prompts did not lead to a difference in reported mood, $F(1,79)=1.3, p=.28, \eta^{2}=.05$.

Furthermore, changes in mood were analysed by investigating the difference between the second 'energy and tiredness' mood scale and the same eight items of the first mood questionnaire. ANOVA did not result in any significant main or interaction effects (all $p s>.05$ ). The absence of changes in mood indicated that participants did not experience a change in mood during the course of the experiment. 


\section{Copyright (C) The British Psychological Society \\ Reproduction in any form (including the internet) is prohibited without prior permission from the Society}

In addition, a regression analysis with the difference between the second 'energy and tiredness' mood scale and the same eight items of the first mood questionnaire as a covariate in the regression analysis revealed a significant main effect of initial self-control, $\beta=0.11, t(79)=3.57, p<.01$, as well as type of priming, $\beta=-0.19$, $t(79)=6.41, p<.01$. In addition, a significant interaction effect was found, $\beta=0.08$, $t(79)=2.65, p=.01$, whereas the covariate failed to reach significance, $\beta=0.01, t(75)=0.09, p=.93$. Together, these findings indicate that differences in physical self-control performance are unlikely to be caused by changes in mood.

Finally, a similar ANOVA on preferred difficulty level yielded no significant main or interaction effect, $F(1,79)<1.0, \eta^{2}=.01$. In other words, participants did not differ in their preferred difficulty for the last task $(M=3.50, S D=0.73)$.

\section{Discussion}

In line with Study 1, the results of Study 2 provided further evidence that activating 'persistence' helps participants to overcome ego depletion. High depleted participants who were exposed to a 'persistence' prime did not display the 'standard' ego depletion pattern. That is, in these participants, no decline in self-control performance was observed. In contrast, high depleted participants who received a neutral prime showed a significant drop in performance on the second self-control measurement.

Interestingly, whereas Study 1 revealed no significant interaction between priming and initial self-control, Study 2 did find an interaction effect. As discussed previously, the pattern of results of Study 1 implies that the ego depletion effect was not overruled completely. However, the interaction effect found in Study 2 suggests that ego depletion can be totally overridden by priming persistence. A possible explanation for these inconsistent findings may lie in the influence of the different priming manipulations. The fact that both high and low depleted participants profited from the persistence prime in Study 1, whereas only high depleted participants were influenced by the prime in Study 2, may imply a relatively stronger influence of the priming procedure used in Study 1.

Study 2 also investigated the effect of priming of persistence on future self-control demands. It was hypothesized that, if exposure to a persistence prime causes people to invest more of their available energy, this should be reflected in a decreased willingness to invest in a subsequent self-control task. This was measured by asking participants to indicate the preferred difficulty level for an additional task. The results show that there are no significant differences among groups; all participants select approximately the same difficulty level. We recognize that this absence of differences between groups is a null effect, which makes it difficult to draw definite conclusions. Yet, it does suggest that future self-control demands are unlikely to neither suffer nor benefit from exposure to the priming manipulation.

\section{GENERAL DISCUSSION}

Successful self-control performance has repeatedly been shown to be dependent on previous acts of self-control. When people exert self-control, they generally perform worse on subsequent self-control tasks. According to the limited energy model, decreasing self-control performance is caused by a limited energy resource. Self-control consumes energy and leads to an automatic depletion of this limited resource, leaving less 


\section{Copyright (C) The British Psychological Society \\ Reproduction in any form (including the internet) is prohibited without prior permission from the Society}

Hugo J. E. M. Alberts et al.

energy available for further successful self-control. In this paper, we questioned whether the automatic emergence of ego depletion can be reduced or even eliminated by means of manipulations that are known to operate at the same automatic level as the occurrence of ego depletion itself. Whereas previous studies have shown that self-control can be improved by means of explicit manipulations that require conscious attention or processing, the current experiments investigated whether the same effects can be accomplished by ways that do not require conscious attention or awareness to be effective (Martijn et al., 2002; Muraven \& Slessarava, 2003). We investigated this by conducting two studies in which we activated the behavioural concept of persistence by means of different priming procedures. The results of both studies reveal that activation of the behavioural concept of persistence can have significant effects on self-control. Depleted participants who were primed with persistence performed significantly better on a subsequent self-control task than depleted participants who were exposed to a neutral prime (Study 1). These results were replicated in Study 2 by means of a different priming procedure. Priming of persistence caused initially depleted participants to overcome ego depletion: their performance on a subsequent self-control task remained equal. In contrast, depleted participants who were exposed to the neutral prime displayed the classic ego depletion pattern: their performance dropped significantly.

To summarize, in line with recent studies on ego depletion and self-control, we have demonstrated that enactment of self-control does not inevitably lead to poorer performance on subsequent tasks. Ego depletion can be overcome when a behavioural construct that is essential to successful self-control becomes activated. Moreover, the present studies show that no conscious awareness of this activation is required.

One important question concerns the underlying processes of the present findings. Although we have shown the influence of priming, little is known about the exact nature of these manipulations in relation to the self-control process. There are several possible explanations for the control enhancing effects we found. To begin with, activating persistence might somehow encourage people to use up their last energy resources. However, Study 2 showed that depleted individuals who were primed with persistence did not differ in their preference for difficulty on a third self-control task. In other words, even when priming causes people to invest more energy in a second control task, they are not more likely to choose a lower difficulty level on a third control task. This indicates that these people are not inclined to make things easier because of energy depletion or because of their need to save a last amount of energy. Moreover, one might argue that the effect of priming continues to work on the final self-control task. If this view is correct, differences should be observed because depleted people who benefit from the control enhancing manipulations should prefer a higher difficulty on a third control task than depleted people who are not primed. As the results of Study 2 made clear, this is not the case. Another possible reason for the absence of any differences between groups on final control tasks may be that priming does not fully deplete the energy resource and therefore does not lead to any significant difference in performance on or difficulty preference for a third task. However, the limited energy model is silent about the total amount of energy that people have. As a consequence, the possibility that a self-control task may not have depleted the energy system is difficult to test. Even when no differences in performance are found after exposure to a large number of depleting self-control tasks, one still might argue that total depletion is not reached. In other words, the limited energy model is not easy to falsify and questions arise when testability comes into play. For instance, it remains questionable whether 


\section{Copyright (C) The British Psychological Society \\ Reproduction in any form (including the internet) is prohibited without prior permission from the Society}

a complete depletion of the energy resource is (a) ever the case and (b) can be manipulated within an experimental setting.

Another mechanism that may underlie our findings is that priming may restore the depleted self. In other words, activating persistence possibly replenishes the depleted self. In that case, self-control can best be regarded as an interactive process, in which the presence of a self-control enhancing state of mind functions as an important moderator. Clearly, this issue warrants further research.

Finally, the current findings may be explained in terms of implicit beliefs or expectancies. Heightened activity of the concept 'persistence' might resemble guidance by positive self-control related beliefs. In other words, a person who is primed with persistence may behave in the same way as a person whose most dominant expectancies are characterized by motivation, self-efficacy and so on. In a previous study, we found some evidence that people distinguish between two classes of beliefs about exercising self-control (Martijn et al., 2002, Expt 2). The first class of beliefs characterizes self-control as energy and comes close to the limited energy model of Baumeister and colleagues. Thus, people expect and believe that they have only a limited amount of energy available for their self-control operations and that they are likely to fail when demands are too high. Furthermore, laymen believe that for optimal performance one needs to be well rested and free of other self-control demands. At the same time, albeit to a lesser extent, people adhere to the belief that self-control is primarily a matter of motivation: if you really want to you can do it, and if you really make an effort you can do much more than you think. Moreover, the distinction between these two classes of beliefs about self-control was recently corroborated by a comparable classification by Mukhopadhyay and Johar (2005), who showed that participants who think that self-control is an unlimited and malleable ability tend to set more goals. The issue is also reminiscent of the concept of self-efficacy (Bandura, 1986) in the sense that people who believe that self-control is a matter of motivation may be expected to experience more control in a self-control demanding situation than people who believe that their capacity to control themselves depends on their energy level. A similar impact of beliefs on self-control was demonstrated in three different studies by Tice, Bratslavsky, and Baumeister (2001). It was shown that, when participants believe their moods are susceptible to change, they respond to bad moods by increasing several impulsive behaviours such as eating, procrastination and immediate gratification. However, when people are led to believe that their moods cannot be repaired by enacting impulsive behaviours, all these effects are eliminated. In summary, the abovediscussed studies raise the possibility that implicit theories or expectations underlie the current findings. However, future research should address this issue more directly by, for instance, considering the role and impact of interpersonal differences in self-control related beliefs and their impact on self-control.

\section{Limitations}

In the present series of studies, we used different supraliminal priming procedures in order to activate persistence-related concepts. Although supraliminal priming procedures may reduce demand characteristic and other self-presentational concerns, they do not warrant complete elimination of these side-effects. A possible solution of this limitation may be offered by the implementation of subliminal priming procedures. With regard to future research, it seems worthwhile to consider whether the current findings can be replicated by the implementation of subliminal manipulations. 


\section{Copyright (C) The British Psychological Society \\ Reproduction in any form (including the internet) is prohibited without prior permission from the Society}

Hugo J. E. M. Alberts et al.

The use of subliminal priming procedures may also provide a stronger test for the currently hypothesized influence of automaticity.

Another limitation of the present research concerns the way we tested the effect of priming on future self-control demands. In Study 2, this issue was addressed by asking participants to indicate the preferred difficulty level for an additional task. It was hypothesized that, if exposure to a persistence prime causes people to invest more of their available energy, this should be reflected in a decreased willingness to invest in a subsequent self-control task. The results revealed that there were no significant differences among groups; all participants select approximately the same difficulty level. As discussed before, this suggests that the possible explanation that priming encourages people to use up their last energy resources seems unlikely. Although this finding is in line with previous research (Martijn et al., 2002), three critical points can be raised with regard to the finding of this null effect. First, it is possible the sensitivity to detect interpersonal differences was not sufficient in the current method of testing. Second, we used a method that was based on introspection. By asking people to select a difficulty level, people have to rely on their experienced depletion. However, their scores on the subjective mood scales show that, even when objective signs of depletion are present (e.g. worse performance on physical self-control tasks), people still report no significant differences on the fatigue-related items. Therefore, it remains possible that the current results reflect the inability of participants to correctly report their mood or inner states of fatigue. Third, asking people to select a level may have caused them to adopt a middle course. In other words, the primary reason to select a particular level may be based less on their state of depletion and more on their need to conform to the standard norm. Future research should consider the limitations concerning the way we tested this hypothesis by, for instance, measuring future self-control performance instead of preference. Moreover, future research is likely to benefit from exploring alternative, more affirmative ways of testing whether participants expend their last energy resources after activation of persistence, for instance by implementing an additional exposure to persistence primes during the final task.

\section{Acknowledgements}

This work was supported by a grant of the Netherlands Organization for Scientific Research (NWO, Grant No. 402-01-049).

\section{References}

Araya, T., Akrami, N., Ekehammar, B., \& Hedlund, L. E. (2002). Reducing prejudice through priming of control-related words. Experimental Psychology, 49, 222-227.

Bandura, A. (1986). The explanatory and predictive scope of self-efficacy theory. Journal of Social and Clinical Psychology, 4, 359-373.

Bargh, J. A., \& Chartrand, T. L. (2000). The mind in the middle: A practical guide to priming and automaticity research. In H.T. Reis \& C.M. Judd (Eds.)., Handbook of research methods in social and personality psychology (pp. 253-285). New York: Cambridge University Press.

Bargh, J. A., Chen, M., \& Burrows, L. (1996). Automaticity of social behavior: Direct effects of trait construct and stereotype activation on action. Journal of Personality and Social Psychology, $71,230-244$.

Bargh, J. A., Gollwitzer, P. M., Lee-Chai, A. Y., Barndollar, K., \& Troetschel, R. (2001). The automated will: Nonconscious activation and pursuit of behavioral goals. Journal of Personality and Social Psychology, 81, 1014-1027. 


\title{
Copyright (C) The British Psychological Society
}

\author{
Reproduction in any form (including the internet) is prohibited without prior permission from the Society
}

Barkley, R. A. (1997). ADHD and the nature of self-control. New York: Guilford Press.

Baumeister, R. F., Bratslavsky, E., Muraven, M., \& Tice, D. M. (1998). Ego depletion: Is the active self a limited resource? Journal of Personality and Social Psychology, 74, 1252-1265.

Baumeister, R. F., Heatherton, T. F., \& Tice, D. M. (1994). Losing control: How and why people fail at self-regulation. San Diego, CA: Academic Press.

Baumeister, R. F., Muraven, M., \& Tice, D. M. (2000). Ego depletion: A resource model of volition, self-regulation, and controlled processing. Social Cognition, 18, 130-150.

Ciarocco, N. J., Sommer, K. L., \& Baumeister, R. F. (2001). Ostracism and ego depletion: The strains of silence. Personality and Social Psychology Bulletin, 27, 1156-1163.

Faber, R. J., \& Vohs, K. O. (2004). To buy or not to buy? Self-control and self-regulatory failure to purchase behavior. In K.D. Vohs \& R.F. Baumeister (Eds.), Handbook of self-regulation (pp. 509-524). New York: Guilford Press.

Gollwitzer, P. M. (1999). Implementation intentions: Strong effects of simple plans. American Psychologist, 54, 493-503.

Holding, D. H. (1983). Fatigue. In G. R. J. Hockey (Ed.), Stress and fatigue in buman performance. Chichester: Wiley.

Martijn, C., Tenbült, P., Merckelbach, H., Dreezens, E., \& De Vries, N. K. (2002). Getting a grip on ourselves: Challenging expectancies about loss of energy after self-control. Social Cognition, 20, 441-458.

Mayer, J. D., \& Gaschke, Y. N. (1988). The experience and meta-experience of mood. Journal of Personality and Social Psychology, 55, 102-111.

Mukhopadhyay, A., \& Johar, G. V. (2005). Where there is a will, is there a way? Effects of lay theories of self-control on setting and keeping resolutions. Journal of Consumer Research, 31, 779-786.

Muraven, M., \& Baumeister, R. F. (2000). Self-regulation and depletion of limited resources: Does self-control resemble a muscle? Psychological Bulletin, 126, 247-259.

Muraven, M., \& Slessareva, E. (2003). Mechanism of self-control failure: Motivation and limited resources. Personality and Social Psychology Bulletin, 29, 894-906.

Muraven, M., Tice, D. M., \& Baumeister, R. F. (1998). Self-control as limited resource: Regulatory depletion patterns. Journal of Experimental and Social Psychology, 74, 774-789.

Schmeichel, B. J., Vohs, K. D., \& Baumeister, R. F. (2003). Intellectual performance and ego depletion: Role of the self in logical reasoning and other information processing. Journal of Personality and Social Psychology, 85, 33-46.

Shah, J. Y., \& Kruglanski, A. W. (2002). Priming against your will: How goal pursuit is affected by accessible alternatives. Journal of Experimental Social Psychology, 38, 368-383.

Shallice, T., \& Burgess, P. (1993). Supervisory control of action and thought selection. In A. Baddeley \& L. Weiskrantz (Eds.), Attention: Selection, awareness, and control (pp. 171-187). Oxford: Oxford University Press.

Srull, T. K., \& Wyer, R. S., Jr. (1979). The role of category accessibility in the interpretation of information about persons: Some determinants and implication. Journal of Personality and Social Psychology, 37, 1660-1667.

Tice, D. M., Bratslavsky, E., \& Baumeister, R. F. (2001). Emotional distress regulation takes precedence over impulse control: If you feel bad, do it! Journal of Personality and Social Psychology, 80, 53-67.

Webb, T. L., \& Sheeran, P. (2003). Can implementation intentions help to overcome egodepletion? Journal of Experimental Social Psychology, 39, 279-286.

Received 3 I May 2005; revised version received 27 June 2006 